\title{
QUALIDADE DO SUCO DE MARACUJÁ-AMARELO EM DIFERENTES PONTOS DE COLHEITA E APÓS O AMADURECIMENTO
}

\author{
Quality of yellow passion fruit juice in different harvest points and after ripening
}

\author{
Antonione Araujo Coelho', Sergio Agostinho Cenci², Eder Dutra de Resende ${ }^{3}$
}

\begin{abstract}
RESUMO
Conduziu- se este trabalho, com o objetivo de avaliar a qualidade do suco de maracujá-amarelo (Passiflora edulis Sims. f. flavicarpa Degener) com diferentes pontos de colheita e, após o completo amadurecimento em câmara de armazenamento, visando à comercialização in natura ou a industrialização. Foram determinados os teores de acidez titulável, ácido ascórbico, sólidos solúveis, açúcares redutores e não-redutores e o valor de $\mathrm{pH}$. As médias foram comparadas quanto ao intervalo de confiança com $5 \%$ de significância e $10 \%$ de desvio em torno da média amostral de população infinita. Os resultados mostraram que o ponto adequado para a colheita dos maracujás-amarelos da safra de inverno foi identificado quando pelo menos $30,7 \%$ da superfície da casca estavam amareladas. Nesse ponto, eles apresentaram características químicas adequadas para o consumo in natura ou para sustentar o processo fisiológico de amadurecimento do fruto durante o armazenamento.
\end{abstract}

Termos para indexação: Passiflora edulis, vitamina C, acidez total, açúcares redutores e não-redutores.

\begin{abstract}
This work had as an objective to evaluate the quality of yellow passion fruit juice (Passiflora edulis Sims. f. flavicarpa Degener) in different harvest points and after complete ripening in a storage chamber, intended for natural consumption or sales of derived products. We determined the levels of titratable acidity, ascorbic acidy, soluble solids, reducer and non-reducer sugars and $\mathrm{pH}$ value. The averages were compared regarding confidence intervals with a 5\% significance and $10 \%$ deviation around the sampling average of infinite population. The results showed that an adequate harvest point of the yellow passion fruits from the winter season was identified when at least $30.7 \%$ of the peel surface was yellowish. At this point they presented appropriated chemical characteristics for consumption in natura or to support the physiological ripening process during storage.
\end{abstract}

Index Terms: Passiflora edulis, vitamin C, total acidity, reducer and non-reducer sugars.

(Recebido em 27 de agosto de 2008 e aprovado em 29 de maio de 2009)

\section{INTRODUÇÃO}

A fruticultura é, atualmente, um dos segmentos mais importantes da agricultura brasileira, respondendo por 25 $\%$ do valor da produção agrícola nacional. Nos últimos anos, aumentou sua área a uma taxa nunca vista, ampliando suas fronteiras em direção à região nordeste, onde condições de luminosidade, umidade relativa e temperatura são mais favoráveis do que nas regiões Sul e Sudeste (Lacerda et al., 2004).

O maracujazeiro é uma frutífera da família Passifloraceae e do gênero Passiflora, bastante cultivada e explorada de norte a sul do território brasileiro e com bom retorno econômico. O maracujá-amarelo ou maracujáazedo (Passiflora edulis Sims. f. flavicarpa Degener) é nativo da América do Sul e é amplamente cultivado em países tropicais e subtropicais (Lima, 2002). Os maiores produtores mundiais se localizam na América do Sul, onde o Brasil, a Colômbia, o Peru e o Equador são os maiores exportadores de frutos. Segundo dados do Instituto Brasileiro de Geografia e Estatística-IBGE (2008), a produção brasileira, em 2006, chegou a 615.196 toneladas de frutos em uma área plantada de 44.363 hectares, com rendimento médio de $13.867 \mathrm{kgha}^{-1}$. Os maiores estados produtores são: Bahia, Espírito Santo, São Paulo, Minas Gerais, Sergipe e Rio de Janeiro.

O maracujá-amarelo tem despertado grande interesse dos fruticultores, face à sua rápida produção em relação a outras frutíferas e a sua grande aceitação no mercado. Ele é usado para consumo in natura e para a industrialização, pois a importância econômica do fruto é representada pelo suco integral a $14^{\circ} \mathrm{Brix}$ e pelo néctar e suco concentrado a $50^{\circ} \mathrm{Brix}$. Seu suco é muito consumido, em razão do valor nutritivo, sabor e aroma exótico e característico, aroma e acidez acentuados, sendo também utilizado em diversos

\footnotetext{
${ }^{1}$ Universidade Estadual do Norte Fluminense Darcy Ribeiro/ UENF - Laboratório de Tecnologia de Alimentos/CCTA - Campos dos Goytacazes, RJ ${ }^{2}$ Embrapa Agroindústria de Alimentos - Guaratiba, RJ

3Universidade Estadual do Norte Fluminense Darcy Ribeiro/ UENF - Laboratório de Tecnologia de Alimentos/CCTA - Campos dos Goytacazes, RJ eresende@uenf.br
} 
produtos como sorvete, mousses e bebidas alcoólicas, fazendo com que ocupe o segundo lugar em vendas no mercado nacional (Araújo et al., 1974; Machado et al., 2003).

Os maracujás-amarelos demandados pelo mercado "in natura" e para fins industriais devem apresentar acidez titulável de $3,2 \%$ a 4,5\%, conteúdo de sólidos solúveis acima de $14{ }^{\circ}$ Brix, rendimento em suco a partir de $33 \%$, teor

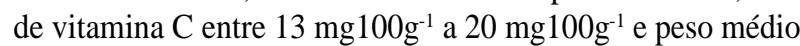
dos frutos acima de $120 \mathrm{~g}$ (Haendler, 1965; Ruggiero et al., 1996; São José et al., 1999; Costa, 2001). Durante a maturação dos frutos, uma das principais modificações em suas características é o acúmulo de açúcares (glicose, frutose e sacarose), o qual ocorre simultaneamente com a redução da acidez. O teor de açúcares atinge o máximo no final da maturação, conferindo excelência à qualidade do produto (Chitarra \& Chitarrra, 2005).

A correta determinação do estádio de maturação do fruto é essencial para que a colheita seja efetuada no momento adequado. Para isso, são utilizados os índices de maturação que compreendem características de coloração da casca ou alterações químicas que ocorrem ao longo do processo de maturação dos frutos, tais como acidez titulável (AT), sólidos solúveis (SS), conteúdo de açúcares, relação SS/AT, rendimento em suco, vitamina C, clorofila e carotenóides totais do suco. Os índices de maturação devem assegurar a obtenção de frutos de boa qualidade no que se refere às características sensoriais durante o armazenamento, visando ao melhor aproveitamento do potencial de comercialização deste fruto (Kluge et al., 2002).

A colheita do maracujá é, geralmente, efetuada quando os frutos caem no chão. Esse procedimento pode levar à desidratação do fruto e à contaminação por microrganismos, reduzindo o seu período de conservação e de comercialização, acarretando perdas significativas. Porém, o ponto ideal de colheita do maracujá ainda é incerto, influenciando na qualidade, nos componentes do aroma e na vida de prateleira dos frutos (Vieira, 1997). Surge, então, a necessidade de se avaliar a colheita de frutos mais verdes, em melhores condições fitossanitárias e padronizados para a obtenção de uma matéria-prima de melhor qualidade e mais uniforme para o armazenamento e a industrialização, reduzindo as perdas.

Neste trabalho, objetivou-se avaliar a qualidade do suco de maracujá-amarelo por meio das características químicas de frutos com diferentes pontos de colheita e após o completo amadurecimento, visando à comercialização in natura ou industrialização.

\section{MATERIAL E MÉTODOS}

Utilizaram-se frutos de maracujá-amarelo (Passiflora edulis Sims. f. flavicarpa Degener), colhidos numa lavoura localizada no município de Campos dos Goytacazes-RJ. A área plantada é de 1,38 há, possui uma declividade de $0-5 \%$ e solo do tipo areno-argiloso. $\mathrm{O}$ sistema de condução das plantas é do tipo espaldeiras com 1 fio e distância entre linhas de plantio de 3,5 metros e 4 metros de distância entre plantas, com densidade populacional de 833 plantas/ha. O sistema de polinização foi manual e o de irrigação foi do tipo gotejamento, com intervalo de 8 dias entre irrigações. A colheita dos frutos foi feita de maio a agosto de 2008 (safra de inverno), sendo caracterizada por uma precipitação de $53 \pm 10 \mathrm{~mm}$ de chuva, temperatura de $21 \pm 1,5^{\circ} \mathrm{C}$ e umidade relativa de $80 \pm 5 \%$ UR.

$\mathrm{Na}$ colheita, os frutos foram selecionados visualmente de forma a apresentarem o mesmo tamanho ( \pm 200 g) e o seguinte padrão de maturação: estádio 1, com coloração verde intensa e brilhante; estádio 2, com coloração verde-clara; estádio 3, coloração com pequena mancha amarela definida; estádio 4 , com $2 / 4$ da casca de coloração amarela; estádio 5, com 3/4 da casca de coloração amarela; estádio 6, casca com pequena mancha verde; estádio 7, fruto com casca totalmente amarelada.

A coloração da casca foi medida usando-se o Colorímetro Hunterlab MiniScan Spectrophotometer (MiniScan XE Plus), sendo realizada em dois pontos equidistantes da face exposta e não-exposta do fruto, compreendendo a região mediana entre a parte superior (pedúnculo) e a inferior (base) dos frutos. A escala de cor foi obtida conforme Silva (2004), utilizando os valores do parâmetro de Hunter b. A percentagem de cor amarela foi obtida pela diferença entre a média das determinações da cor para cada estádio de maturação e o estádio verde inicial, dividida pela diferença máxima da média das medidas do parâmetro de Hunter $b$ de frutos totalmente maduros e dos frutos verdes.

Após a colheita, os frutos foram imediatamente transportados para o laboratório onde foram submetidos a uma lavagem e sanitização com água clorada $(100 \mathrm{~mL} 1000 \mathrm{~L}-$ ${ }^{1}$ de cloro ativo) e secos. Metade do lote, compreendendo 20 maracujás para cada estádio de maturação, foi caracterizada no dia da colheita. A outra metade foi estocada a $22{ }^{\circ} \mathrm{C}$ e $90 \%$ UR por tempo variado até o completo amadurecimento do fruto, quando, foram novamente avaliados quanto às características químicas. Os frutos colhidos maduros serviram como parâmetro de referência de qualidade. 
A acidez titulável foi determinada utilizando-se cerca de $2 \mathrm{~g}$ de suco diluído em água destilada até $25 \mathrm{~mL}$ e titulado com $\mathrm{NaOH}$ a $0,1 \mathrm{molL}^{-1}$, conforme a metodologia descrita pela Association of Official Agricultural Chemists-AOAC (1998). A determinação do teor de ácido ascórbico (AA) também foi feita pelo método preconizado pela AOAC (1998), utilizando $2 \mathrm{~mL}$ de suco e com resultados expressos em mg de AA por $100 \mathrm{~mL}$ de suco. As determinações dos teores de sólidos solúveis (SS) foram feitas utilizando-se gotas de suco, com leitura direta em refratômetro digital marca ATAGO modelo PR-201, com correção automática dos valores em função da temperatura e os resultados expressos em ${ }^{\circ}$ Brix.

A determinação dos teores de açúcares redutores (AR) foi feita por meio do método Eynon Lane (Lane \& Eynon, 1934), que emprega o licor de Soxhlet, com título padronizado utilizando-se solução de glicose a $5 \%$. Procedeu-se a titulação dos açúcares redutores contidos em $10 \mathrm{~mL}$ de suco de maracujá, adicionado de $40 \mathrm{~mL}$ de água destilada. Os resultados foram expressos em gramas de AR por $100 \mathrm{~mL}$ de suco. A determinação dos teores de açúcares redutores totais (ART) foi feita em hidrolisado neutralizado com $\mathrm{NaOH}$ a $1 \mathrm{molL}^{-1}$. A concentração de ART foi obtida pela titulação deste extrato, conforme descrito anteriormente e os resultados expressos em gramas de ART por $100 \mathrm{~mL}$ de suco. O conteúdo de açúcares nãoredutores (ANR) foi obtido pela diferença entre os conteúdos de ART e AR, com resultados expressos em gramas de ANR por $100 \mathrm{~mL}$ de suco.

Utilizou-se um teste estatístico segundo o método de amostragem simples ao acaso (ASA), com $5 \%$ de significância. As médias foram comparadas utilizando-se o teste por intervalo de confiança. O tamanho da amostra foi dimensionado para uma população infinita de frutos, considerando além do nível de significância, o desvio de $10 \%$ em torno da média amostral, para todas as características analisadas.

\section{RESULTADOS E DISCUSSÃO}

Os sete estádios de maturação relacionados subjetivamente com os diferentes pontos de colheita foram determinados pela escala de cor da casca, caracterizada pelo parâmetro de Hunter $b$, e identificados como: estádio 1, com $0 \%$ de área da casca amarelada; estádio 2, com 5,1 $\%$ de área amarelada; estádio 3, com 30,7 \% de área amarelada; estádio 4, com 40,3\% de área amarelada; estádio 5, com 66,1 \% de área amarelada; estádio 6, com 74,7 \% de área amarelada; e estádio 7, com 98,4 \% de área da casca amarelada.
Os resultados estatísticos mostraram que, durante o período de amadurecimento dos frutos, ocorreram diferenças significativas entre os teores de acidez do suco dos maracujás após a colheita e após a estocagem, para cada estádio de maturação (Figura 1). No estádio 7, os frutos já estavam plenamente maduros. Observou-se um maior consumo de ácidos orgânicos, durante o amadurecimento dos frutos provenientes dos estádios 1 e 2 , que tinham $0 \%$ e 5,1\% de cor amarela. Isso pode ser atribuído à maior taxa metabólica do fruto e modificações no tecido da casca, conforme descrito por Shiomi et al. (1996).

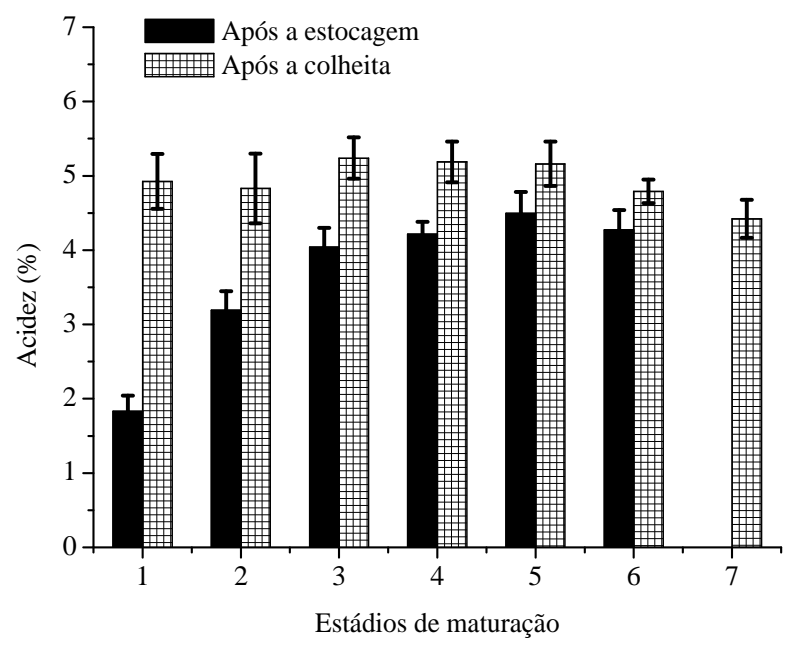

Figura 1 - Acidez titulável (\%) do suco de maracujásamarelos colhidos em 7 estádios de maturação, avaliados após a colheita e ao final do período de completo amadurecimento a $22{ }^{\circ} \mathrm{C}$ e $90 \%$ UR. As barras verticais representam os intervalos de confiança ao nível de 0,05\%.

Os valores médios de acidez do suco de maracujásamarelos, analisados após o período de estocagem, mostraram diferenças significativas somente para os frutos colhidos nos estádios 1 e 2, quando comparados com os frutos colhidos maduros (estádio 7). Nota-se que, a partir do estádio 3, os valores de acidez dos frutos avaliados após a estocagem não apresentaram diferenças significativas em relação aos frutos totalmente maduros, que atingiram valores médios de 4,42\%.

Com relação aos frutos analisados após a colheita, verifica-se na Figura 1 que ocorreu uma pequena redução na acidez entre o estádio mais verde $(4,93 \%)$ e o estádio completamente maduro, alcançando valores médios de 4,42 $\%$. Resultados semelhantes foram encontrados por Marchi et al. (2000), Resende et al. (2001) e Silva et al. (2005), em 
maracujá-amarelo, por Shiomi et al. (1996) em maracujároxo e Silva et al. (1999) em maracujá-doce, os quais verificaram maiores teores de ácidos orgânicos nos frutos mais "verdes" e um pequeno decréscimo ao final do amadurecimento.

Os valores médios de $\mathrm{pH}$ do suco de maracujásamarelos, analisados ao final da estocagem, mostraram diferenças significativas para os estádios 1 e 2, quando comparados com o estádio 7 (frutos colhidos maduros). Nota-se que, a partir do estádio 3, os valores de $\mathrm{pH}$ do suco não apresentaram diferenças significativas com relação aos frutos totalmente maduros, que atingiram valores médios de 2,92 (Figura 2).

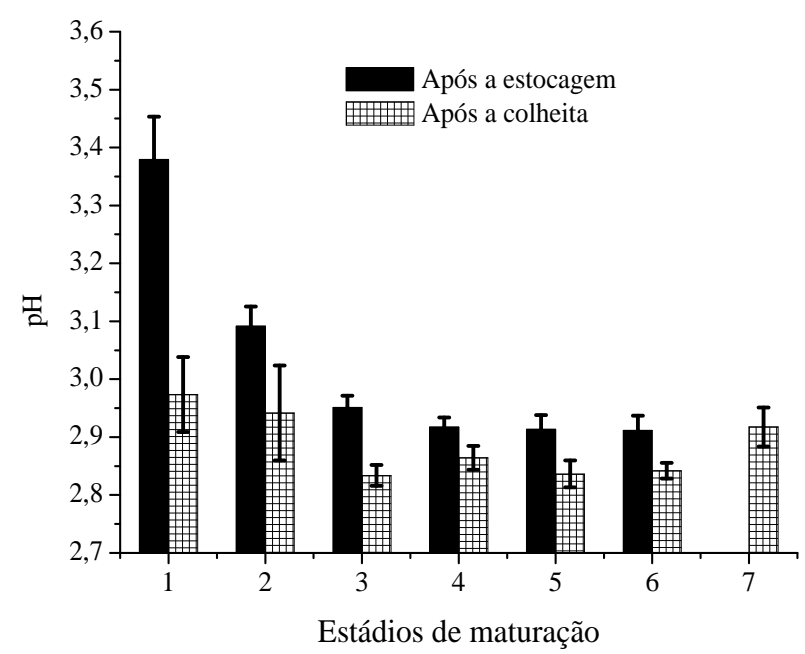

Figura 2 - pH do suco de maracujás-amarelos colhidos em 7 estádios de maturação, avaliados após a colheita e ao final do período de completo amadurecimento a $22^{\circ} \mathrm{C}$ e $90 \%$ UR. As barras verticais representam os intervalos de confiança ao nível de $0,05 \%$.

Os maiores valores de $\mathrm{pH}$ do suco para os frutos provenientes dos estádios 1 e 2 são inversamente proporcionais aos menores valores de acidez. Segundo Silva et al. (2005), ocorre uma pequena redução dos valores de $\mathrm{pH}$ nos primeiros estádios de maturação do maracujáamarelo, permanecendo constante a partir do estádio com $30 \%$ de coloração da casca amarelada. Para frutos de maracujá-doce, Silva et al. (1999) verificaram uma redução de $\mathrm{pH}$ nos estádios iniciais do amadurecimento e um posterior incremento nos estádios finais de amadurecimento.

Não se detectaram diferenças entre os teores médios de ácido ascórbico do suco dos frutos analisados após a colheita e após a estocagem, para os diferentes estádios de maturação, exceto para os estádios 1 e 2 . Nesses dois estádios mais verdes, ocorreu um consumo significativo do ácido ascórbico durante o processo de amadurecimento dos frutos, atingindo valores mais baixos do que a média de $21,7 \mathrm{mg} 100 \mathrm{~mL}^{-1}$ encontrada nos frutos colhidos maduros (Figura 3). Esse consumo excessivo do ácido ascórbico pode estar relacionado à intensa taxa metabólica que ocorre nos frutos colhidos nos estádios imaturos (Shiomi et al., 1996).

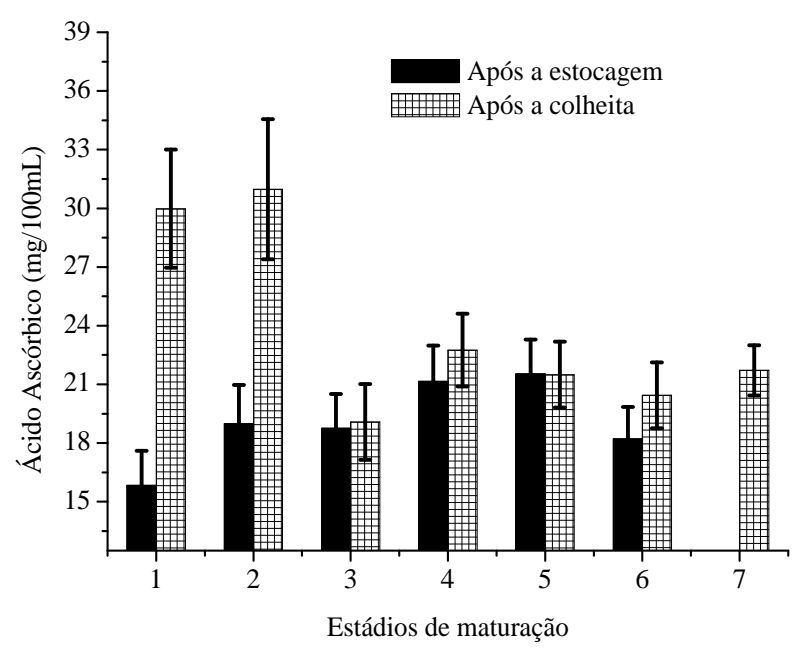

Figura 3 - Ácido ascórbico $\left(\mathrm{mg} 100 \mathrm{~mL}^{-1}\right)$ do suco de maracujás-amarelos colhidos em 7 estádios de maturação, avaliados após a colheita e ao final do período de completo amadurecimento a $22{ }^{\circ} \mathrm{C}$ e $90 \%$ UR. As barras verticais representam os intervalos de confiança ao nível de $0,05 \%$.

Os frutos de maracujá-amarelo analisados após a colheita, a partir do estádio 3 (30,7 \% de cor amarela), não apresentaram diferenças significativas quanto aos teores de ácido ascórbico, em relação ao estádio maduro (Figura 3). Silva et al. (1999) verificaram que os frutos de maracujádoce colhidos em estádio pré-climatérico, que se caracterizava pela mudança da coloração verde-clara para amarela na base do fruto, apresentaram uma diminuição de aproximadamente $50 \%$ no conteúdo de ácido ascórbico, durante 28 dias de estocagem a $9^{\circ} \mathrm{C}$ e $85-90 \%$ UR, atingindo $8,33 \mathrm{mg} 100 \mathrm{~mL}^{-1}$ de suco. Tais resultados contrastam com os obtidos neste trabalho uma vez que os teores de ácido ascórbico não se reduziram nos frutos estocados em estádios de maturação com mais de $30,7 \%$ de cor da casca amarelada. Verifica-se, portanto, que a colheita dos frutos em estádio fisiológico maturo é essencial para a 
preservação do conteúdo de ácido ascórbico do suco, durante $\mathrm{o}$ armazenamento.

Nota-se, na Figura 4, que não houve diferença significativa entre as médias de SS do suco dos frutos analisados após a colheita em diferentes estádios de maturação, exceto para os estádios 1 e 2 que apresentaram médias inferiores aos demais estádios. Observa-se que, para os frutos analisados após a estocagem, somente a partir do estádio 3 (30,7\% de cor amarela) os valores médios de SS mostraram-se iguais, mas superiores aos dos estádios 1 e 2 , alcançando valores de $14,5^{\circ}$ Brix, que é um nível apreciado pelas indústrias, pois permite um melhor rendimento tecnológico.

Segundo Marchi et al. (2000), os frutos de maracujáamarelo apresentando mais de $30 \%$ de coloração amarela da casca já teriam teores de sólidos solúveis suficientes para serem colhidos diretamente da planta. Resende et al. (2001) verificaram que frutos de maracujá-amarelo colhidos no estádio pré-climatérico e estocados por 35 dias a $10^{\circ} \mathrm{C}$ não apresentaram alterações no conteúdo de SS, concordando com os resultados deste trabalho. No caso de frutos de maracujá-roxo colhidos com mais de 60 dias após a antese, Shiomi et al. (1996) verificaram que ocorreu uma pequena redução do conteúdo de SS do suco, durante a estocagem a $25^{\circ} \mathrm{C}$.

Conforme Aular et al. (2000), os frutos de maracujá-amarelo só atingem maturidade mínima quando possuem mais de $20 \%$ de área da casca com coloração amarelada, em aproximadamente 63 dias após a antese, momento em que apresenta $14,1 \%$ de SS. Enquanto que os frutos verdes, com menos de $20 \%$ de cor amarela na casca (53 dias após a antese), apresentam apenas 11,7 $\%$ de SS.

$\mathrm{Na}$ avaliação do teor de AR do suco dos frutos, após a colheita e após a estocagem em diferentes estádios de maturação, verificou-se diferença entre as médias somente para os estádios 1 e 2. Nota-se, na Figura 5, que, tanto na ocasião da colheita quanto ao final da estocagem, os valores médios de AR não diferiram a partir do estádio 3 , quando comparados com os frutos colhidos maduros. Nos estádios 1 e 2, o suco dos frutos de maracujá-amarelo analisados após a estocagem apresentaram as menores médias de AR, em torno de 1,5 a $2,5 \mathrm{~g} 100 \mathrm{~mL}^{-1}$, e os frutos colhidos maduros apresentaram uma média de AR de 4,9 $\mathrm{g} 100 \mathrm{~mL}^{-1}$. Isso indica que a colheita foi feita em estádios imaturos, o que não permitiu o acúmulo total de açúcares redutores, reduzindo a fonte de substratos diretos utilizados no processo metabólico de amadurecimento do fruto.

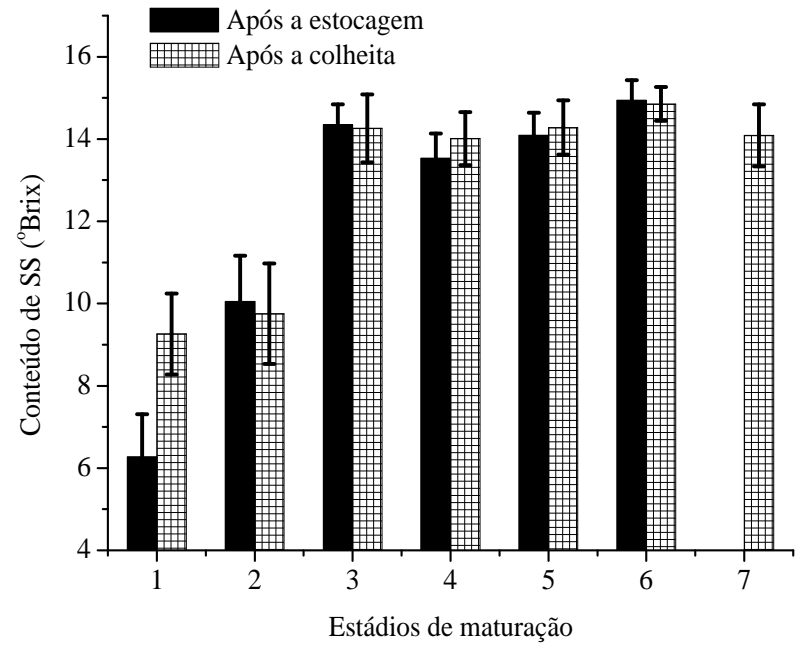

Figura 4 - Sólidos solúveis $\left({ }^{\circ}\right.$ Brix) do suco de maracujás-amarelos colhidos em 7 estádios de maturação, avaliados após a colheita e ao final do período de completo amadurecimento a $22^{\circ} \mathrm{C}$ e $90 \%$ UR. As barras verticais representam os intervalos de confiança ao nível de $0,05 \%$.

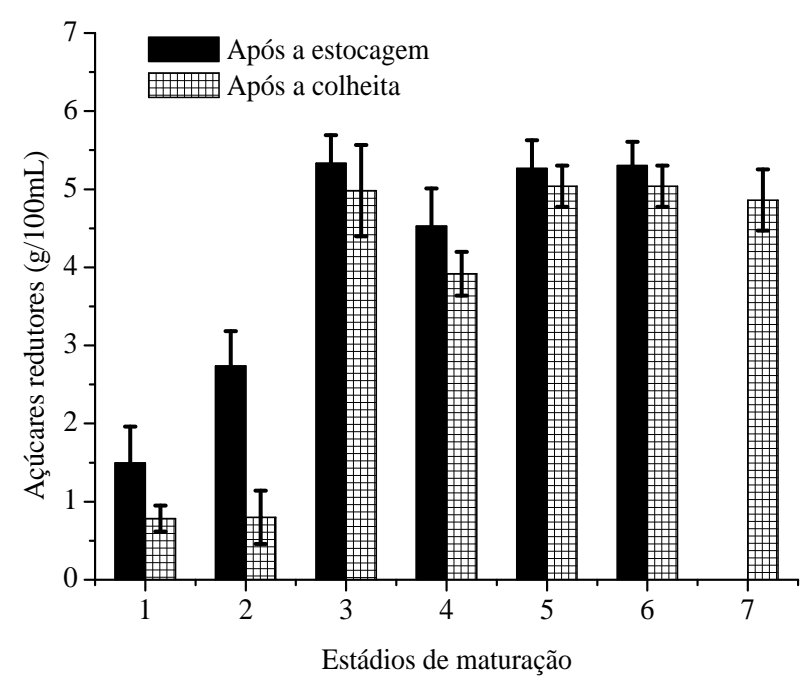

Figura 5 - Açúcares redutores AR $\left(\mathrm{g} 100 \mathrm{~mL}^{-1}\right)$ do suco de maracujás-amarelos colhidos em 7 estádios de maturação, avaliados após a colheita e ao final do período de completo amadurecimento a $22{ }^{\circ} \mathrm{C}$ e $90 \%$ UR. As barras verticais representam os intervalos de confiança ao nível de $0,05 \%$.

Machado et al. (2003) encontraram concentrações de 3,6\% de açúcares redutores em maracujá-amarelo com aproximadamente $50 \%$ de coloração amarela da casca. 
Essa concentração é inferior àquelas obtidas nesse experimento para os frutos colhidos a partir de $30,7 \%$ de coloração amarela da casca, que apresentaram uma média geral de 5,11\% nos frutos avaliados após a colheita.

O conteúdo de ART após a colheita aumentou do estádio 1 até o 6 (74,7\% de coloração amarela), quando o suco atingiu valores médios de $9,6 \mathrm{~g} 100 \mathrm{~mL}^{-1}$. No entanto, no estádio de maturação $3(30,7 \%$ de coloração amarela) os frutos apresentaram $8,2 \mathrm{~g} 100 \mathrm{~mL}$ ${ }^{1}$ de ART, alcançando valores adequados para sustentar o metabolismo do fruto. Nota-se, na Figura 6, que o conteúdo de ART do suco nos estádios mais verdes (1 e 2) não ultrapassou $3,5 \mathrm{~g} 100 \mathrm{~mL}^{-1}$ nos frutos analisados após a colheita.

Em frutos de maracujá-amarelo colhidos após a abscisão natural e estocados a $6{ }^{\circ} \mathrm{C}$, Gama et al. (1991) verificaram que o conteúdo de açúcares redutores totais reduziu-se de $9,27 \mathrm{~g} 100 \mathrm{~mL}^{-1}$ para $8,4 \mathrm{~g} 100 \mathrm{~mL}^{-1}$, em 42 dias de armazenamento. Resende et al. (2001) verificaram que os maracujás-amarelos armazenados a $10{ }^{\circ} \mathrm{C}$, em embalagens de PVC, não alteraram a concentração de ART durante 35 dias de armazenamento, mantendo valores médios de 8,04 g100 $\mathrm{mL}^{-1}$. Segundo Machado et al. (2003), os maracujás-amarelos colhidos com aproximadamente $50 \%$ de coloração amarela apresentaram um conteúdo de $11,1 \%$ de ART.

O conteúdo de ANR, após a colheita, igualou-se ao conteúdo de ART nos dois primeiros estádios de maturação, conforme pode ser observado na Figura 6. Isto pode ser decorrente da presença de reservas de carboidratos na forma de amido para sustentar o processo de amadurecimento do fruto. Segundo Somogyi et al. (1996), o suco de maracujá-roxo contém aproximadamente $2 \%$ de amido. Neste trabalho, a média de ANR nos dois primeiros estádios de maturação foi da ordem de 2,8 g100 $\mathrm{mL}^{-1}$ de suco.

O conteúdo de ANR após a colheita permaneceu constante nos 5 primeiros estádios de maturação, a partir do qual ocorreu um pequeno incremento até o estádio 6 , alcançando uma média de $4,4 \mathrm{~g} 100 \mathrm{~mL}^{-1}$. Isso indica que, durante o amadurecimento, ocorreu um acúmulo mínimo de ANR como fonte de reserva bioquímica. A concentração de ART aumentou expressivamente a partir do estádio 3 (30,7 \% de cor amarela), em razão da grande contribuição da fração de AR no suco do maracujá-amarelo (Figura 5). Isso representa uma fonte de energia livre e disponível para sustentar o processo metabólico do amadurecimento após a colheita.

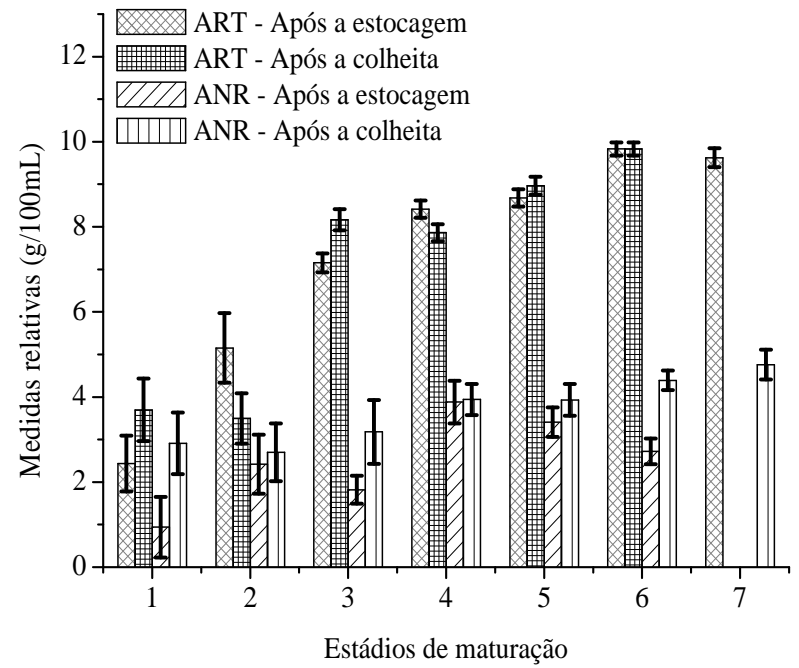

Figura 6 - Açúcares redutores totais (ART) e açúcares não-redutores (ANR) do suco de maracujás-amarelos colhidos em 7 estádios de maturação, avaliados após a colheita e ao final do período de completo amadurecimento a $22{ }^{\circ} \mathrm{C}$ e $90 \%$ UR. As barras verticais representam os intervalos de confiança ao nível de $0,05 \%$.

\section{CONCLUSÃO}

O ponto ótimo para a colheita do maracujá-amarelo da safra de inverno foi identificado quando os frutos atingiram 30,7 \% de área de superfície da casca amarelada, apresentando parâmetros de qualidade do suco adequados para o consumo in natura.

Os frutos colhidos com pelo menos $30,7 \%$ de coloração amarelada da casca amadureceram plenamente durante o armazenamento a $22{ }^{\circ} \mathrm{C}$ e $90 \%$ UR e atingiram os mesmos padrões de qualidade de frutos colhidos totalmente maduros, alcançando a seguinte composição química: $\mathrm{AT}(4,10 \pm 0,26 \%), \mathrm{pH}(2,95 \pm 0,02), \mathrm{AA}(18,75 \pm$ $1,75 \mathrm{mg}^{\left.100 \mathrm{~mL}^{-1}\right), \mathrm{SS}}\left(14,3 \pm 0,50^{\circ} \mathrm{Brix}\right), \operatorname{ANR}(1,82 \pm 0,33$

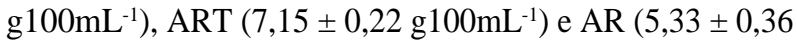
$\left.\mathrm{g} 100 \mathrm{~mL}^{-1}\right)$.

Frutos colhidos nos estádios de maturação 1 e 2 estavam imaturos e com uma baixa qualidade química do suco, tanto por ocasião da colheita como ao final da estocagem por 31 e 22 dias, respectivamente.

\section{AGRADECIMENTOS}

À Faperj pelo apoio financeiro, ao CNPq pelos recursos financiados ao projeto CTAGRO/Edital MCT/ $\mathrm{CNPq}^{\circ}{ }^{\circ}$ 04/2006 - Processo no 554408/2006-6, ao Sr. Jaime Viana pela matéria-prima e à CAPES pela bolsa de pesquisa. 


\section{REFERÊNCIAS BIBLIOGRÁFICAS}

ARAÚJO, C.M.; GAVA, A.J.; ROBBS, P.G.; NEVES, J.F.; MAIA, P.C.B. Características industriais do maracujá (Passiflora edulis var. flavicarpa ) e maturação do fruto. Pesquisa Agropecuária Brasileira, Brasília, v.9, n.9, p.65-69, 1974.

\section{ASSOCIATION OF OFFICIALANALYTICAL} CHEMISTRY. Methods of analyses of the Association of Official Analytical Chemistry. 11.ed. Washington, 1998. $1015 p$.

AULAR, J.; RUGGIERO, C.; DURIGAN, J.F. Influência da idade na colheita sobre as características dos frutos e do suco de maracujá-amarelo. Revista Brasileira de Fruticultura, Jaboticabal, v.22, p.6-8, 2000. Número especial.

CHITARRA, M.I.F.; CHITARRA, A.B. Pós-colheita de frutos e hortaliças: fisiologia e manuseio. Lavras: UFLA, 2005. 785p.

COSTA, J.R.M.; LIMA, C.A.A.; LIMA, E.D.P.A.; CAVALCANTE, L.F.; OLIVEIRA, F.K.D.

Caracterização dos frutos de maracujá amarelo irrigados com água salina. Revista Brasileira de Engenharia Agrícola e Ambiental, Campina Grande, v.5, n.1, p.143-146, 2001.

GAMA, F.S.N.; MANICA, I.; KIST, H.G.K.; ACCORSI, M.R. Aditivos e embalagens de polietileno na conservação do maracujá amarelo armazenado em condições de refrigeração. Pesquisa Agropecuária Brasileira, Brasília, v.26, n.3, p.305-10, 1991.

HAENDLER, L. La passiflora: sa composition chimique et ses possibilités de transformation. Fruits, Paris, v.20, n.5, p.235-245, 1965.

\section{INSTITUTO BRASILEIRO DE GEOGRAFIA E} ESTATÍSTICA. 2006. Disponível em: <http:// 'www.sidra.ibge.gov.br/bda/agrict'

'defaultasp?z=t\&o=10\&i=P . Acesso em: 10 fev. 2008.

KLUGE, R.A.; NACHTIGAL, J.C.; BILHALVA, A.B. Fisiologia e manejo pós-colheita de frutos de clima temperado. 2.ed. Pelotas: UFPEL, 2002. 163p.

LACERDA, M.A.D.; LACERDA, R.D.; ASSIS, P.C. de O. A participação da fruticultura no agronegócio brasileiro.
Revista de Biologia e Ciências da Terra, Campina Grande, v.4, n.1, 2004.

LANE, J.H.; EYNON, L. Determination of reducing sugars by Fehling's solution with methylene blue. London: N.Rodge, 1934. 8p.

LIMA, A.A. Maracujá produção: aspectos técnicos. Brasília: Embrapa Informação Tecnológica, 2002. 103p. (Frutas do Brasil, 15).

MACHADO, S.S.; CARDOSO, R.L.; MATSUURA, F.C.A.U.; FOLEGATTI, M.I.S. Caracterização física e físico-química de frutos de maracujá amarelo provenientes da região de Jaguaquara. Magistra, Cruz das Almas, v.15, n.2, p.229-233, 2003.

MARCHI, R.; MONTEIRO, M.; BENATO, E.A.; SILVA, C.A.R. Uso da cor da casca como indicador de qualidade do maracujá amarelo (Passiflora edulis Sims. f.

flavicarpa Deg.) destinado à industrialização. Ciência e Tecnologia de Alimentos, Campinas, v.20, n.3, p.381-387, 2000.

RESENDE, J.M.; BOAS, E.V.B.V.; CHITARRA, M.I.F. Uso de atmosfera modificada na conservação pós-colheita do maracujá amarelo. Ciência e Agrotecnologia, Lavras, v.25, n.1, p.159-168, 2001.

RUGGIERO, C.; SÃO JOSE, A.R.; VOLPE, C.A.; OLIVEIRA, J.C.; DURIGAN, J.F.; BAUNGARTNER, J.G; SILVA, J.R.; NAKAMURA, K.; FERREIRA, M.E.; KAVATI, R.; PEREIRA, V.P. Maracujá para exportação: aspectos técnicos da produção. Brasília: Embrapa-SPI, 1996. 64p. (Publicações técnicas Frupex, 19).

SÃO JOSÉ, A.R.; REBOUÇAS, T.N.H.; BONFIM, M.P.; PIRES, M.M. Situação regional da cultura do maracujáNordeste. In: REUNIÃO TÉCNICA DE PESQUISA EM MARACUJAZEIRO, 1999, Londrina. Anais... Londrina: IAPAR/SBF, 1999. p.4-10.

SHIOMI, S.; WAMOCHO, L.S.; AGONG, S.G.; Ripening characteristics of purple passion fruit on and off the vine. Postharvest Biology and Technology, Amsterdam, v.7, p.161-170, 1996.

SILVA, A.P.; VIEITES, R.L.; CEREDA, E. Conservação de maracujá doce pelo uso de cera e choque a frio. Scientia Agrícola, Piracicaba, v.56, n.4, 1999. 
SILVA, T.V. Efeito da época de colheita e do estádio de maturação sobre as características físicas e químicas do maracujá amarelo (Passiflora edulis f. flavicarpa Degener). 2004. 83p. Dissertação (Mestrado em Produção Vegetal)-Universidade Estadual do Norte Fluminense Darcy Ribeiro, Campos dos Goytacazes, 2004.

SILVA, T.V.; RESENDE, E.D.; VIANA, A.P.; ROSA, R.C.C.; PEREIRA, S.M.F.; CARLOS, L.A.;

VITORAZI, L. Influência dos estádios de maturação na qualidade do suco do maracujá-amarelo. Revista
Brasileira de Fruticultura, Jaboticabal, v.27, n.3, p.472-475, 2005.

SOMOGYI, L.P.; BARRETT, D.M.; HUI, Y.H. Processing fruits: science and technology: major processed products. Basel: Technomic, 1996. v.2, 558p.

VIEIRA, G. Fisiologia pós-colheita do amadurecimento do maracujá-amarelo (Passiflora edulis f. flavicarpa

Degener). 1997. 88p. Tese (Doutorado em Ciências)-

Faculdade de Ciências Farmacêuticas, Universidade de São Paulo, São Paulo, 1997. 